\title{
Validation of Canadian mothers' recall of events in labour and delivery with electronic health records
}

\author{
Uilst Bat-Erdene ${ }^{1}$, Amy Metcalfe ${ }^{2}$, Sheila W McDonald ${ }^{1}$, Suzanne C Tough ${ }^{1,2^{*}}$
}

\begin{abstract}
Background: Maternal report of events that occur during labour and delivery are used extensively in epidemiological research; however, the validity of these data are rarely confirmed. This study aimed to validate maternal self-report of events that occurred in labour and delivery with data found in electronic health records in a Canadian setting.

Methods: Data from the All Our Babies study, a prospective community-based cohort of women's experiences during pregnancy, were linked to electronic health records to assess the validity of maternal recall at four months post-partum of events that occurred during labour and delivery. Sensitivity, specificity and kappa scores were calculated. Results were stratified by maternal age, gravidity and educational attainment.

Results: Maternal recall at four months post-partum was excellent for infant characteristics (gender, birth weight, gestational age, multiple births) and variables related to labour and delivery (mode of delivery, epidural, labour induction) (sensitivity and specificity $>85 \%$ ). Women who had completed a university degree had significantly better recall of labour induction and use of an epidural.

Conclusion: Maternal recall of infant characteristics and events that occurred during labour and delivery is excellent at four months post-partum and is a valid source of information for research purposes.
\end{abstract}

\section{Introduction}

Maternal report of events that occurred during labour and delivery are used extensively in epidemiological research. Self-report data are commonly collected as they can be obtained efficiently and at less cost than medical chart reviews; furthermore, self-report allows researchers to simultaneously collect other data that may not be available in medical charts or other source documents, such as lifestyle information [1-4]. Although maternally reported data about the events occurring during labour and delivery are widely used, the validity of this data is rarely confirmed. To our knowledge, maternal recall of birth events has not been validated in a Canadian population and few studies have involved electronic health records.

According to previous studies, the validity of maternal recall varies based on the type of information [2-6], the

\footnotetext{
* Correspondence: suzanne.tough@albertahealthservices.ca

'Department of Paediatrics, University of Calgary, Calgary, Alberta, Canada Full list of author information is available at the end of the article
}

way questions were worded [7], mothers' socio-economic status $[1,8,9]$, and length of time since the event $[9,10]$. Other studies, specifically those examining maternal recall of infant birth weight, suggest that age, parity, time since birth and ethnicity do not affect the validity of maternal recall $[1,11]$.

The majority of validation studies have focused on maternal recall of infant birth weight, gestational age and/ or mode of delivery [1-6,8-19]. Generally, they have found that maternal recall for these variables is excellent. A US study found that $89 \%$ of 46,637 women sampled could recall their infant's birth weight within one ounce when compared to the weight recorded on the medical charts [13], while a British study found that $91 \%$ of 649 mothers were able to recall their infant's birth weight within $200 \mathrm{~g}$ compared to medical charts [16]. Another study conducted in the UK, determined that $94.5 \%$ of 8037 women could recall their infants gestational age at birth within one week of the gestational age found in the medical charts [8]. Other studies showed that maternal recall of 
gestational age is less accurate than their recall of birth weight, but concluded that maternal recall of both gestational age and birth weight are valid $[1,2,6,9,15,19]$. Several studies examining vaginal vs. caesarean delivery also found high agreement (typically $>90 \%$ ) between medical charts and maternal report $[5,7,10,12,15,17]$. In contrast, conflicting results $[5,7,15]$ have been found for use of forceps during delivery. While one Australian study reported that maternal recall for the use of forceps was 99.7\% [7], another Australian study found that only $63.6 \%$ of mothers could accurately recall if forceps were used [5].

The aim of this study was to validate maternal self-report at four months post-partum of events that occurred during labour and delivery with data from electronic health records (EHRs) in a Canadian setting. This validation is important because several large birth cohorts [20-22] have been recently developed in Canada, all of which obtained data through questionnaires. Additionally, national surveys conducted by Statistics Canada, such as the Canadian Community Health Survey $[23,24]$ and the Maternity Experience Survey [25,26], also rely on maternal recall of events that occurred during labour and delivery and data from EHRs are not always accessible for research purposes due to cost and time restraints that may prohibit access.

\section{Methods}

Self-reported data on birth outcomes was obtained from the All Our Babies (AOB) study, a prospective community-based cohort of women's experiences during pregnancy and the post-partum period. Pregnant women were recruited through physicians' practices, laboratory services, and posters in the community, and were eligible to participate if they were at most 24 weeks and 6 days gestation at the time of recruitment, receiving prenatal care in Calgary, and able to complete the questionnaires in English $(n=4,003)$ [27]. Participants were asked to complete three written questionnaires: the first before 24 weeks of gestation, the second between 34 and 36 weeks, and the third at four months post-partum. Data for this study comes from the questionnaire that women completed at four months post-partum. In total, 3,388 women completed at least one questionnaire, with a retention rate of $85 \%$. A more detailed description of the AOB methodology can be found in McDonald et al [27]. Ethical approval for the AOB study was granted by the University of Calgary's Conjoint Health Research Ethics Board.

Pregnancy and birth outcome data were obtained directly from electronic health records (EHR) for the hospital admission for labour and delivery. EHRs include data on antenatal risk factors and events that occurred during labour and delivery [28]. Deterministic linkage based on maternal personal health number (PHN), name and other unique identification factors were used to link data from the AOB study with the EHRs. A total of 2,859 women were identified in both datasets. We were unable to link approximately $15 \%$ of participants due to missing or erroneous personal health numbers (primary reason), missing postpartum questionnaire data, or delivery outside of hospital without a registered midwife.

Data elements from the $\mathrm{AOB}$ questionnaires and the EHR were reviewed, and eight common variables (caesarean delivery, epidural usage, gestational age, infant birth weight, infant gender, labour induction, multiple gestation pregnancy, preterm birth) were identified. Gestational age and birth weight were examined as both continuous and categorical variables. Gestational age was categorized as preterm ( $<37$ weeks), term (37-40 weeks) and post-term ( $\geq 41$ weeks) [29]. Low birth weight was defined as birth weight less than $2500 \mathrm{~g}$.

Validation of the maternal self-report with the EHR was measured by calculating the sensitivity and specificity for measuring bias, and kappa score for measuring precision [18]. Kappa coefficients were considered to represent excellent agreement if the value was greater than 0.75 , moderate agreement if the value was between 0.40 to 0.75 and poor agreement if the value was less than 0.40 [12]. The validity of maternal recall for continuous data elements was determined by calculating the proportion of mothers who reported the gestational age and birth weight within one week and $50 \mathrm{~g}$ increments.

To determine if socio-demographic factors influenced maternal recall, a series of stratified analyses were also conducted by highest level of education (university vs. high school), gravidity (primigravida vs. multigravida), and maternal age at delivery ( $<35$ vs. $\geq 35$ ). Data on gravidity and education were obtained from the $\mathrm{AOB}$ questionnaire and data on maternal age at delivery was obtained from the EHRs. Sensitivity and specificity were compared and values where the $95 \%$ confidence intervals did not overlap were considered to be significantly different at $\alpha=0.05$ level. Chi square tests were used to examine differences in demographic variables between women whose questionnaire data could and could not be linked to EHRs. All analyses were conducted in Stata SE Version 11.

\section{Results}

Characteristics of participants identified in both the AOB dataset and EHRs are described in Table 1. Most of the women reported completing a university education, being in a relationship, and having a household income of $\$ 40,000$ Canadian or greater. Data from the Maternity Experience Survey indicated that $75.3 \%$ of the mothers nationally, compared to $88.6 \%$ of the women in this study, have an annual household income of at least $\$ 40,000$ Canadian [30]. Additionally, data from Statistics Canada indicate that nationally $61.5 \%$ of women have completed a university degree compared to $74.9 \%$ seen 
Table 1 Characteristics of women $(\mathrm{N}=2,859)$

\begin{tabular}{cc}
\hline Variable & N (\%) \\
\hline Ethnicity & $2,249(78.7)$ \\
Caucasian & \\
Employment status & \\
Employed & 2,660 (93.0) \\
Non-employed & \\
Highest level of education obtained (3.0) \\
Less than high school \\
College or university \\
Graduate school \\
Home ownership \\
Income \\
Language spoken at home \\
Marital status \\
Mother's place of birth \\
Number of babies delivered
\end{tabular}

$$
\text { One }
$$

$2,657(92.9)$

Note: Due to item non-response $\mathrm{N}$ does not equal 2,859 for all variables and percentages do not sum to $100 \%$

in this sample [31]. Significant differences were observed among women whose questionnaires could and could not be linked to EHRs. Women whose questionnaire data could not be linked to EHRs were significantly less likely to be employed, married or in a common-law relationship, over age 35 at the time of delivery, to own their own homes, to have delivered their infant in a hospital. They also had lower educational attainment and household incomes. No differences were observed based on country of birth, ethnicity, language spoken at home, and gravidity (results not shown).

Table 2 shows the overall agreement between selfreported data from the AOB cohort and information from the EHR. Maternal recall at four months post-partum was found to be valid with high sensitivity, specificity and kappa scores for all variables. Sensitivity and specificity were greater than $90 \%$ for the majority of variables studied. The variables of epidural usage, labour induction, and post-term births had lower sensitivity and specificity than the other variables studied; however, sensitivity and specificity were all greater than $80 \%$.

When examined as continuous variables, the majority of women could accurately recall their infant's gestational age and birth weight within a margin of error, although exact recall was low. Out of 2,677 mothers, $71.5 \%$ of the mothers recalled the exact gestational age of their infant, while $98.3 \%$ of the mothers remembered the gestational age of their infant within two weeks (Table 3). At four months post-partum, the exact birth weight of the infant was recalled by $11.6 \%$ of 2,552 mothers, and $91.7 \%$ of the mothers remembered the birth weight of their infant within $200 \mathrm{~g}$ (Table 4). The inability of mothers to recall exact gestational age and birth weight has implications when calculating rates of common perinatal outcomes. The prevalence of low birth weight and post-term birth was significantly higher in the AOB data than in the EHRs (Table 5).

Stratified analysis revealed that women who had completed a university degree had significantly greater recall of whether their labour was induced (sensitivity $=90.1$, 95\% CI: 87.3-92.4) and epidural usage (sensitivity $=92.3$,

Table 2 Validity of self-reported data compared to electronic health records

\begin{tabular}{|c|c|c|c|c|c|c|c|c|}
\hline $\begin{array}{l}\text { Variable } \\
\text { description }\end{array}$ & Prevalence & $\begin{array}{l}\text { Sensitivity } \\
(95 \% \mathrm{Cl})\end{array}$ & $\begin{array}{l}\text { Specificity } \\
(95 \% \mathrm{Cl})\end{array}$ & $\begin{array}{c}\text { True } \\
\text { Positives N }\end{array}$ & $\begin{array}{c}\text { False } \\
\text { Positives } \mathrm{N}\end{array}$ & $\begin{array}{c}\text { False } \\
\text { Negatives } \mathrm{N}\end{array}$ & $\begin{array}{c}\text { True } \\
\text { Negatives } \mathbf{N}\end{array}$ & $\begin{array}{l}\text { Kappa } \\
(95 \% \mathrm{Cl})\end{array}$ \\
\hline Caesarean delivery & 756/2695 (28.1) & $\begin{array}{c}99.7 \\
(99.0,100.0)\end{array}$ & $\begin{array}{c}99.8 \\
(99.6,100.0)\end{array}$ & 706 & 3 & 2 & 1984 & $\begin{array}{c}0.99 \\
(0.99,0.99)\end{array}$ \\
\hline Epidural usage & $\begin{array}{c}1477 / 2859 \\
(51.7)\end{array}$ & $\begin{array}{c}90.7 \\
(89.1,92.2)\end{array}$ & $\begin{array}{c}82.2 \\
(80.1,84.2)\end{array}$ & 1340 & 246 & 137 & 1136 & $\begin{array}{c}0.73 \\
(0.71,0.76)\end{array}$ \\
\hline Infant gender & $\begin{array}{l}\text { Males: 1362/ } \\
2621 \text { (52.0) }\end{array}$ & $\begin{array}{c}99.4 \\
(98.8,99.7) \\
\end{array}$ & $\begin{array}{c}99.0 \\
(98.2,99.5) \\
\end{array}$ & 1274 & 12 & 8 & 1180 & $\begin{array}{c}0.98 \\
(0.98,0.99)\end{array}$ \\
\hline Low birth weight & $159 / 2552(6.2)$ & $\begin{array}{c}96.5 \\
(92.1,98.9)\end{array}$ & $\begin{array}{c}97.8 \\
(97.1,98.3)\end{array}$ & 139 & 53 & 5 & 2355 & $\begin{array}{c}0.82 \\
(0.77,0.86)\end{array}$ \\
\hline Labour induction & $755 / 2796(27.0)$ & $\begin{array}{c}87.3 \\
(84.7,89.6)\end{array}$ & $\begin{array}{c}90.6 \\
(89.2,81.8)\end{array}$ & 659 & 192 & 96 & 1849 & $\begin{array}{c}0.75 \\
(0.72,0.78)\end{array}$ \\
\hline $\begin{array}{l}\text { Multiple gestation } \\
\text { pregnancy }\end{array}$ & 36/2693 (1.3) & $\begin{array}{c}94.3 \\
(80.8,99.3)\end{array}$ & $\begin{array}{c}99.8 \\
(99.6,99.9)\end{array}$ & 33 & 5 & 2 & 2653 & $\begin{array}{c}0.90 \\
(0.83,0.97)\end{array}$ \\
\hline Post-term births & 1373/2677 (51.3) & $\begin{array}{c}94.9 \\
(91.5,97.3)\end{array}$ & $\begin{array}{c}88.5 \\
(87.1,89.7)\end{array}$ & 243 & 279 & 13 & 2142 & $\begin{array}{c}0.57 \\
(0.53,0.61)\end{array}$ \\
\hline Preterm births & 208/2677 (7.8) & $\begin{array}{c}94.8 \\
(90.6,97.5)\end{array}$ & $\begin{array}{c}98.4 \\
(97.8,98.8)\end{array}$ & 182 & 40 & 10 & 2445 & $\begin{array}{c}0.87 \\
(0.83,0.91)\end{array}$ \\
\hline
\end{tabular}


Table 3 Maternal recall of birth weight $(n=2,552)$

\begin{tabular}{ccc}
\hline Difference from exact birth weight $(\mathbf{g})$ & \multicolumn{2}{c}{ Maternal recall } \\
\cline { 2 - 3 } & $\mathbf{n}$ & Percentage (\%) \\
\hline 0.00 & 284 & 11.13 \\
\pm 50.00 & 2256 & 88.40 \\
\pm 100.00 & 2341 & 91.73 \\
\pm 150.00 & 2391 & 93.69 \\
\pm 200.00 & 2413 & 94.55 \\
\hline
\end{tabular}

Table 4 Maternal recall of gestational age $(n=2,677)$

\begin{tabular}{ccc}
\hline $\begin{array}{c}\text { Difference from exact gestational age } \\
\text { (weeks) }\end{array}$ & \multicolumn{2}{c}{ Maternal recall } \\
\cline { 2 - 3 } & $\mathbf{n}$ & $\begin{array}{c}\text { Percentage } \\
\text { (\%) }\end{array}$ \\
\hline 0 & 1913 & 71.46 \\
\pm 1 & 2570 & 96.00 \\
\pm 2 & 2631 & 98.28 \\
\hline
\end{tabular}

95\% CI: 90.6-93.8) compared to women who had only completed high school or less (labour induction: sensitivity $=79.3$, 95\% CI: 72.8-84.8; epidural: sensitivity $=86.6$, 95\% CI: 82.8-89.7) (Table 6). However, no significant difference was found in any of the outcomes studied by maternal age or gravidity (results not shown).

\section{Conclusions}

By comparing the self-reported data from women who participated in the AOB study and electronic health records, it was found that maternal self-report of events occurring around the time of labour and delivery are highly valid when recalled four months after delivery. Educational attainment was the only socio-demographic factor that influenced the accuracy of maternal recall in this study. Although women who had completed university had more accurate recall of labour induction and epidural usage than the mothers who had completed high school, it is worth mentioning that both groups of mothers had high rates of recall. It is plausible that women with higher educational attainment asked more questions during labour and delivery and as such were more aware of events during labour and delivery. The literature is conflicting as to whether women with more education have more accurate recall with some studies showing that more educated women had more accurate recall $[2,5,19]$, and other studies showing no effect of education on validity [9,15-17].

A significant association between validity of recall and maternal age and/or gravidity was not observed in this study. Similarly, other studies have not found an association between maternal age and recall $[9,16,17,19]$. While no studies could be found that assessed the relationship between gravidity and recall, several studies have examined the relationship between parity and maternal recall. Results are conflicting with some studies showing that parity is negatively associated with recall $[1,2]$ while others show that there is no association with parity [3].

In the present study, mothers were able to more accurately report events if they were presented with a list of options (i.e. How was your new baby delivered? A) Vaginally, B) You went into labour but had an emergency caesarean section, C) You did not go into labour and had an emergency caesarean section, D) You had a planned caesarean section) compared to an open or free-text field (i.e. What was your baby's birth weight?). This difference could also be due to the nature of the question asked. Further work that asks participants the same questions with both categorical and open response options is warranted as this may have important implications for researchers as they strive to reduce participant burden and achieve accurate responses.

Despite the large population, this study is not without limitations. As the present analysis was limited to variables that were captured in both datasets, the validity of sociodemographic and lifestyle factors, mental health, and pregnancy complications could not be assessed. Future studies should assess the validity of these and other important perinatal variables. Some stratification factors (gravidity and education) were self-reported and we cannot exclude the possibility of inaccurate reporting. However, significant differences were not observed with gravidity, and due to social desirability, we presume that women would be more likely to report a higher level of educational attainment that would minimize the difference in reporting seen between groups. Finally, this study was limited to women who could complete a written questionnaire in English. This prohibited an analysis of the impact of English fluency on the validity of maternal recall.

Table 5 Impact of maternal recall of continuous variable on categorical outcomes

\begin{tabular}{lll}
\hline Variable & All Our Babies Prevalence $(95 \% \mathrm{Cl})$ & Electronic Health Record Prevalence $(95 \% \mathrm{Cl})$ \\
\hline Low-birth weight & $\mathbf{7 . 5}(\mathbf{6 . 5 , 8 . 5 )}$ & $\mathbf{5 . 6}(\mathbf{4 . 7 , 6 . 4 )}$ \\
Post-term delivery & $\mathbf{1 9 . 5}(\mathbf{1 8 . 0 , 2 1 . 0 )}$ & $\mathbf{9 . 4}(\mathbf{8 . 3 , 1 0 . 4 )}$ \\
Preterm delivery & $8.3(7.2,9.3)$ & $7.3(6.3,8.2)$ \\
\hline
\end{tabular}

Note: Bold values indicate significance at $\alpha<0.05$ 
Table 6 Agreements between maternal self-report and the EHR by mother's highest level of education $(n=2,844)$

\begin{tabular}{|c|c|c|c|c|}
\hline \multirow[t]{3}{*}{ Variable description } & \multirow{2}{*}{\multicolumn{2}{|c|}{$\begin{array}{c}\text { Sensitivity }(\%),(95 \% \mathrm{Cl}) \\
\text { Highest level of education obtained }\end{array}$}} & \multirow{2}{*}{\multicolumn{2}{|c|}{$\begin{array}{c}\text { Specificity }(\%),(95 \% \mathrm{Cl}) \\
\text { Highest level of education obtained }\end{array}$}} \\
\hline & & & & \\
\hline & University & High school & University & High school \\
\hline Caesarean delivery & $99.6(98.7,100)$ & $100(97.7,100)$ & $99.8(99.4,100)$ & $100(99.2,100)$ \\
\hline Epidural usage & $92.3(90.6,93.8)$ & $86.6(82.8,89.7)$ & $82.5(80.1,84.7)$ & $81.3(76.5,85.6)$ \\
\hline Infant birth weight & $99.0(94.7,100)$ & $89.7(75.8,97.1)$ & $98.3(97.6,98.9)$ & $96.0(94.0,97.5)$ \\
\hline Infant gender & $99.4(98.7,99.8)$ & $99.3(97.5,99.9)$ & $98.8(97.8,99.4)$ & $99.6(98.1,100)$ \\
\hline Labour induction & $90.1(87.3,92.4)$ & $79.3(72.8,84.8)$ & $91.2(89.7,92.6)$ & $89.0(85.9,91.6)$ \\
\hline Multiple gestation pregnancy & $93.3(77.9,99.2)$ & $100(39.8,100)$ & $99.9(99.6,100)$ & $99.7(98.8,100)$ \\
\hline Post-term births & $96.0(92.3,98.3)$ & $90.9(80.0,97.0)$ & $88.7(87.1,90.1)$ & $87.6(84.6,90.2)$ \\
\hline Preterm births & $95.3(90.6,98.1)$ & $92.3(79.1,98.4)$ & $98.9(98.3,99.3)$ & $96.7(94.9,98.0)$ \\
\hline
\end{tabular}

Note: Bold values indicate significance at $\alpha<0.05$

In conclusion, maternal recall at four months postpartum of important events that occurred during labour and delivery is excellent. This study fills a gap in literature and shows that self-reported data from Canadian mothers are valid sources of information with comparison to EHR for research purposes.

\section{List of Abbreviations}

AOB: All Our Babies; Cl: Confidence Interval; EHR: Electronic Health Record

\section{Authors' contributions}

SCT designed and secured funding for the overall study. AM and SWM designed the sub-study. UBE and AM conducted the analysis. UBE drafted the manuscript. All authors critically reviewed the manuscript and approved the final version for submission.

\section{Competing interests}

None of the authors have any competing interests to declare

\begin{abstract}
Acknowledgements
This study was funded by Alberta Innovates - Health Solutions, formerly the Alberta Heritage Foundation for Medical Research, as part of the Preterm Birth and Healthy Outcomes Team Interdisciplinary Team Grant (\#200700595). U. Bat-Erdene received a summer scholarship from the Canadian Institutes of Health Research (CIHR) Strategic Training Program in Genetics, Child Development and Health; A. Metcalfe holds a studentship award from the CIHR Strategic Training Program in Genetics, Child Development and Health; S.W. McDonald holds a post-doctoral fellowship award from the Alberta Centre for Child, Family and Youth Health; S.C. Tough holds a senior scientist award from Alberta Innovates - Health Solutions.
\end{abstract}

\section{Declarations}

This article has been published as part of BMC Pregnancy and Childbirth Volume 13 Supplement 1, 2013: Preterm Birth: Interdisciplinary Research from the Preterm Birth and Healthy Outcomes Team (PreHOT). The full contents of the supplement are available online athttp://www. biomedcentral.com/bmcpregnancychildbirth/supplements/13/S1. All of the publication fees will be funded by the Preterm Birth and Healthy Outcomes Team Interdisciplinary Team Grant (\#200700595) from Alberta Innovates - Health Solutions, formerly the Alberta Heritage Foundation for Medical Research.

\section{Author details \\ 'Department of Paediatrics, University of Calgary, Calgary, Alberta, Canada. ${ }^{2}$ Department of Community Health Sciences, University of Calgary, Calgary,} Alberta, Canada.

Published: 31 January 2013

\section{References}

1. Adegboye AR, Heitmann B: Accuracy and correlates of maternal recall of birthweight and gestational age. BJOG : an international journal of obstetrics and gynaecology 2008, 115(7):886-893.

2. Buka SL, Goldstein JM, Spartos E, Tsuang MT: The retrospective measurement of prenatal and perinatal events: accuracy of maternal recall. Schizophrenia research 2004, 71(2-3):417-426.

3. Elkadry E, Kenton K, White P, Creech S, Brubaker L: Do mothers remember key events during labor? American journal of obstetrics and gynecology 2003, 189(1):195-200.

4. Tomeo CA, Rich-Edwards JW, Michels KB, Berkey CS, Hunter DJ, Frazier AL, Willett WC, Buka SL: Reproducibility and validity of maternal recall of pregnancy-related events. Epidemiology 1999, 10(6):774-777.

5. Oates RK, Forrest D: Reliability of mothers' reports of birth data. Australian paediatric journal 1984, 20(3):185-186.

6. Sou SC, Chen WJ, Hsieh WS, Jeng SF: Severe obstetric complications and birth characteristics in preterm or term delivery were accurately recalled by mothers. Journal of clinical epidemiology 2006, 59(4):429-435.

7. Hewson D, Bennett A: Childbirth research data: medical records or women's reports? American journal of epidemiology 1987, 125(3):484-491.

8. Poulsen G, Kurinczuk JJ, Wolke D, Boyle EM, Field D, Alfirevic Z, Quigley MA: Accurate reporting of expected delivery date by mothers 9 months after birth. Journal of clinical epidemiology 2011, 64(12):1444-1450.

9. Seidman DS, Slater PE, Ever-Hadani P, Gale R: Accuracy of mothers' recall of birthweight and gestational age. British journal of obstetrics and gynaecology 1987, 94(8):731-735.

10. Githens PB, Glass CA, Sloan FA, Entman SS: Maternal recall and medical records: an examination of events during pregnancy, childbirth, and early infancy. Birth 1993, 20(3):136-141.

11. Wilcox WD, Gold BD, Tuboku-Metzger AJ: Maternal recall of infant birth weight. Clinical pediatrics 1991, 30(8):509-510.

12. Casey R, Rieckhoff M, Beebe SA, Pinto-Martin J: Obstetric and perinatal events: the accuracy of maternal report. Clinical pediatrics 1992, 31(4):200-204

13. Gayle HD, Yip R, Frank MJ, Nieburg P, Binkin NJ: Validation of maternally reported birth weights among 46,637 Tennessee WIC program participants. Public Health Rep 1988, 103(2):143-147.

14. Hvidtjorn D, Grove J, Schendel D, Schieve LA, Ernst E, Olsen J, Thorsen P: Validation of self-reported data on assisted conception in The Danish National Birth Cohort. Hum Reprod 2009, 24(9):2332-2340.

15. Olson JE, Shu XO, Ross JA, Pendergrass T, Robison LL: Medical record validation of maternally reported birth characteristics and pregnancyrelated events: a report from the Children's Cancer Group. American journal of epidemiology 1997, 145(1):58-67.

16. O'Sullivan JJ, Pearce MS, Parker L: Parental recall of birth weight: how accurate is it? Archives of disease in childhood 2000, 82(3):202-203.

17. Quigley MA, Hockley C, Davidson LL: Agreement between hospital records and maternal recall of mode of delivery: evidence from 12391 deliveries in the UK Millennium Cohort Study. BJOG an international journal of obstetrics and gynaecology 2007, 114(2):195-200 
18. Sanderson M, Williams MA, White E, Daling JR, Holt VL, Malone KE, Self SG, Moore DE: Validity and reliability of subject and mother reporting of perinatal factors. American journal of epidemiology 1998, 147(2):136-140

19. Troude P, L'Helias LF, Raison-Boulley AM, Castel C, Pichon C, Bouyer J, de La Rochebrochard E: Perinatal factors reported by mothers: do they agree with medical records? European journal of epidemiology 2008, 23(8):557-564.

20. Gracie SK, Lyon AW, Kehler HL, Pennell CE, Dolan SM, McNeil DA, Siever JE, McDonald SW, Bocking AD, Lye SJ, et al: All Our Babies Cohort Study: recruitment of a cohort to predict women at risk of preterm birth through the examination of gene expression profiles and the environment. BMC pregnancy and childbirth 2010, 10:87.

21. Walker MC, Finkelstein SA, Rennicks White R, Shachkina S, Smith GN Wen SW, Rodger M: The Ottawa and Kingston (OaK) Birth Cohort: development and achievements. Journal of obstetrics and gynaecology Canada : JOGC = Journal d'obstetrique et gynecologie du Canada : JOGC 2011, 33(11):1124-1133.

22. Ontario Health Study. [https://ontariohealthstudy.ca/].

23. Savard $N$, Levallois $P$, Rivest $L P$, Gingras $S$ : A study of the association between characteristics of CLSCs and the risk of small for gestational age births among term and preterm births in Quebec, Canada. Canadian journal of public health Revue canadienne de sante publique 2012, 103(2):152-157.

24. Lega I, Ross NA, Zhong L, Dasgupta K: Gestational diabetes history may signal deprivation in women with type 2 diabetes. J Womens Health (Larchmt) 2011, 20(4):625-629.

25. Chalmers B, Dzakpasu S, Heaman M, Kaczorowski J: The Canadian maternity experiences survey: an overview of findings. Journal of obstetrics and gynaecology Canada: JOGC = Journal d'obstetrique et gynecologie du Canada : JOGC 2008, 30(3):217-228.

26. Dzakpasu S, Kaczorowski J, Chalmers B, Heaman M, Duggan J, Neusy E: The Canadian maternity experiences survey: design and methods. Journal of obstetrics and gynaecology Canada: JOGC = Journal d'obstetrique et gynecologie du Canada : JOGC 2008, 30(3):207-216.

27. McDonald SW, Lyon AW, Benzies KM, McNeil DA, Lye SJ, Dolan SM, Penell CE, Bocking AD, Tough SC: The All Our Babies pregnacy cohort: design, methods, and participant characteristics. BMC Pregnancy Childbirth 2013, 13(Suppl 1):S2.

28. Information management guidelines. [http://www.aphp.ca/pdf/APHP\% 20Data\%20Management\%20Guidelines_October\%202007_.pdf].

29. Delaney MRA: Guidelines for the management of pregnancy at $41+0$ to $42+0$ weeks. Journal of obstetrics and gynaecology Canada : JOGC = Journal d'obstetrique et gynecologie du Canada : JOGC 2008, 30(9):800-810.

30. Public Health Agency of Canada: Data Tables - The Maternity Experiences Survey (MES) 2006-2007. Ottawa: Public Health Agency of Canada; 2009.

31. Chart 8: Percentage of women among university graduates, by program level, Canada, 1992 to 2008. [http://www.statcan.gc.ca/pub/89-503-x/ 2010001/article/11542/c-g/c-g008-eng.htm].

doi:10.1186/1471-2393-13-S1-S3

Cite this article as: Bat-Erdene et al:: Validation of Canadian mothers' recall of events in labour and delivery with electronic health records. BMC Pregnancy and Childbirth 2013 13(Suppl 1):S3.

\section{Submit your next manuscript to BioMed Central and take full advantage of:}

- Convenient online submission

- Thorough peer review

- No space constraints or color figure charges

- Immediate publication on acceptance

- Inclusion in PubMed, CAS, Scopus and Google Scholar

- Research which is freely available for redistribution

Submit your manuscript at www.biomedcentral.com/submit
Biomed Central 